\title{
Effect of the Nitrogen Ions Implantation Mode on the Structure-Phase Transformations in Graphite Cast Irons
}

\author{
${ }^{1}$ Evgenij R. Akst, ${ }^{2}$ Lenar N. Shafigullin, ${ }^{3}$ Irina F. Shaekhova \\ ${ }^{1-3}$ Kazan Federal University \\ Email:ev.akst@yandex.ru; misharin_82@mail.ru; irrra1603@yandex.ru
}

Received: $2^{\text {th }}$ August 2019, Accepted: $3^{\text {th }}$ September 2019, Published: $31^{\text {st }}$ October 2019

\begin{abstract}
Using nuclear gamma resonance (Mössbauer) spectroscopy in the backscattering geometry, the surface layers of graphite cast irons irradiated with nitrogen ion fluxes were studied. New phases were discovered and identified that are formed in the surface layers of the studied alloys during the implantation of nitrogen ions. A relationship has been established between the type of new phases, their relative amount and the implantation (irradiation) regime of cast irons. The processes accompanying ion implantation are considered, and the mechanisms of formation of secondary phases in cast irons, taking into account the presence of graphite inclusions in their structure, are proposed. The effect of the density of the ion current (implantation current) on the formation of new phases is studied.
\end{abstract}

Keywords

Graphite Cast Irons, Implantation of Nitrogen Ions, Ion Current Density, Mössbauer Spectroscopy, The Formation of New Phases in the Implanted Layer.

\section{Introduction}

Ion implantation is one of the effective ways to control the properties of materials. In recent decades, the possibilities of ion implantation for modifying the surface properties of metals and alloys have been actively studied, which led to the formation of a new direction in ion-beam technology - implantation metallurgy [1]. Of particular interest is the prospect of modification through ion implantation, in particular, the implantation of nitrogen ions, the surface properties of graphite cast irons. Graphite cast iron is a relatively inexpensive, technologically advanced and widespread structural material. At the same time, the complex chemical composition and the presence of graphite inclusions in the structure force graphite cast irons to be classified as rather complex, inhomogeneous metal systems in which radiation-induced processes can proceed in a special way [2,3]. Currently, the use of nitrogen ion implantation to modify the surface of graphite cast irons is constrained by the lack of scientifically sound recommendations on the choice of irradiation (implantation) regimes, based on the understanding and consideration of all processes that accompany ion implantation. This, in particular, concerns the processes of the formation of new phases in the implanted layer.

\section{Object and Methods of Study}

In this work, cast irons containing graphite inclusions in the structure was irradiated (implanted) with singly charged nitrogen ions with an energy of $40 \mathrm{keV}$ in the dose range from $1 \times 10^{17}$ to $1 \times 10^{18}$ ion $/ \mathrm{cm}^{2}$. When choosing the irradiation regimes, we were guided by the information from the works devoted to the study of the effect of nitrogen ion implantation on the properties and associated phase composition of iron-carbon alloys $[1,4,5,6$, etc.]. To study changes in the structural phase state of the surface layers of cast irons, nuclear gamma resonance (Mössbauer) spectroscopy was used. Mössbauer spectra were measured in backscattering geometry by detecting internal conversion electrons and secondary x-ray radiation. The average depth of exit of electrons of internal conversion (thickness of the probed layer) is comparable with the average path length of nitrogen ions of the indicated energy implanted into the material. When registering secondary $\mathrm{x}$-ray radiation, the thickness of the probed layer is two orders of magnitude greater. This makes it possible to obtain information on the structure and phase composition of both the implanted surface layer and the deeper layers adjacent to it.

\section{Results and Discussion}

Our previous studies [8-12] showed that at the same doses of nitrogen ion implantation, more secondary nitrogencontaining phases are formed in graphite cast irons than in technically pure iron and low-carbon steel. Among the new phases, $\varepsilon$-type phases ( $\varepsilon$-nitrides and carbonitrides) predominate, the amount of which depends on the shape of graphite inclusions, which affects the effect of increasing microhardness and wear resistance of irradiated cast irons. These studies have allowed us to conclude that graphite inclusions in cast irons play an essential role in the mechanism of formation of secondary phases.

Ion implantation leads to the formation of a large number of point radiation defects in the surface layers of the irradiated material $[1,2,7]$. At high doses of radiation (implantation), which are characteristic of our studies, a significant part of these defects leaves the zone of their generation and goes to the places of effective capture (to the places of runoff of defects). Obviously, in graphite cast irons the role of such effective sinks is played by the boundaries of graphite inclusions. The flow of radiation defects to drains carries with it silicon atoms dissolved in iron, as well as atoms of 
introduced nitrogen. The accumulation of impurity atoms in sinks, known as the phenomenon of radiation-induced segregation, increases the probability of the formation of secondary phases here.

As for $\varepsilon$-type nitrides and carbides, they have a hexagonal crystal lattice similar to a graphite lattice. In addition, the nitrogen and carbon atoms in these compounds are interchangeable components, the content of which can vary over a fairly wide range of $\left(\varepsilon-\mathrm{Fe}_{2}+\mathrm{x}(\mathrm{N}, \mathrm{C})\right.$, where $\left.0<\mathrm{x}<3.2\right)$. Obviously, under nonequilibrium conditions of ion implantation, the formation of such compounds at the boundaries of graphite inclusions is preferable from the thermodynamic and kinetic points of view. A certain role in the mechanism of formation of new phases, in addition to the phenomenon of radiation-induced segregation, can be played by the effect of ionic mixing.

Since lamellar graphite inclusions, in comparison with spherical graphite inclusions, have a higher specific surface area, more new nitrogen-containing phases are formed in lamellar cast iron upon implantation of nitrogen ions than in nodular cast iron. We have associated with this a higher effect of increasing the microhardness and wear resistance of these cast irons $[9,10]$.

One of the most important parameters of the ion implantation process, along with the target temperature and the dose of its irradiation (D), is the ion current density (j). Changing the implantation current density can significantly affect the nature of radiation-induced processes in irradiated materials and thereby affect their structural-phase composition and properties [1,3]. Despite this, the problem of the influence of the ion current density is still poorly understood.

Taking into account the foregoing, in the present work, a set of implantation doses for cast irons containing lamellar graphite inclusions in the structure was performed at two ion current densities differing by an order of magnitude: $j=5$ $\mu \mathrm{A} / \mathrm{cm}^{2}$ and $\mathrm{j}=50 \mu \mathrm{A} / \mathrm{cm}^{2}$. Such a change in the implantation regime significantly affects the change in the form of NGR spectra.

The NGR spectra of the samples in the initial state are a superposition of sextets typical of ferrite, corresponding to atomic configurations with a different number of silicon atoms in the immediate environment $\mathrm{Fe}^{57}$. In addition to the ferritic component, a line sextet characteristic of cementite is also observed in the spectra (Fig. 1a, 2a).

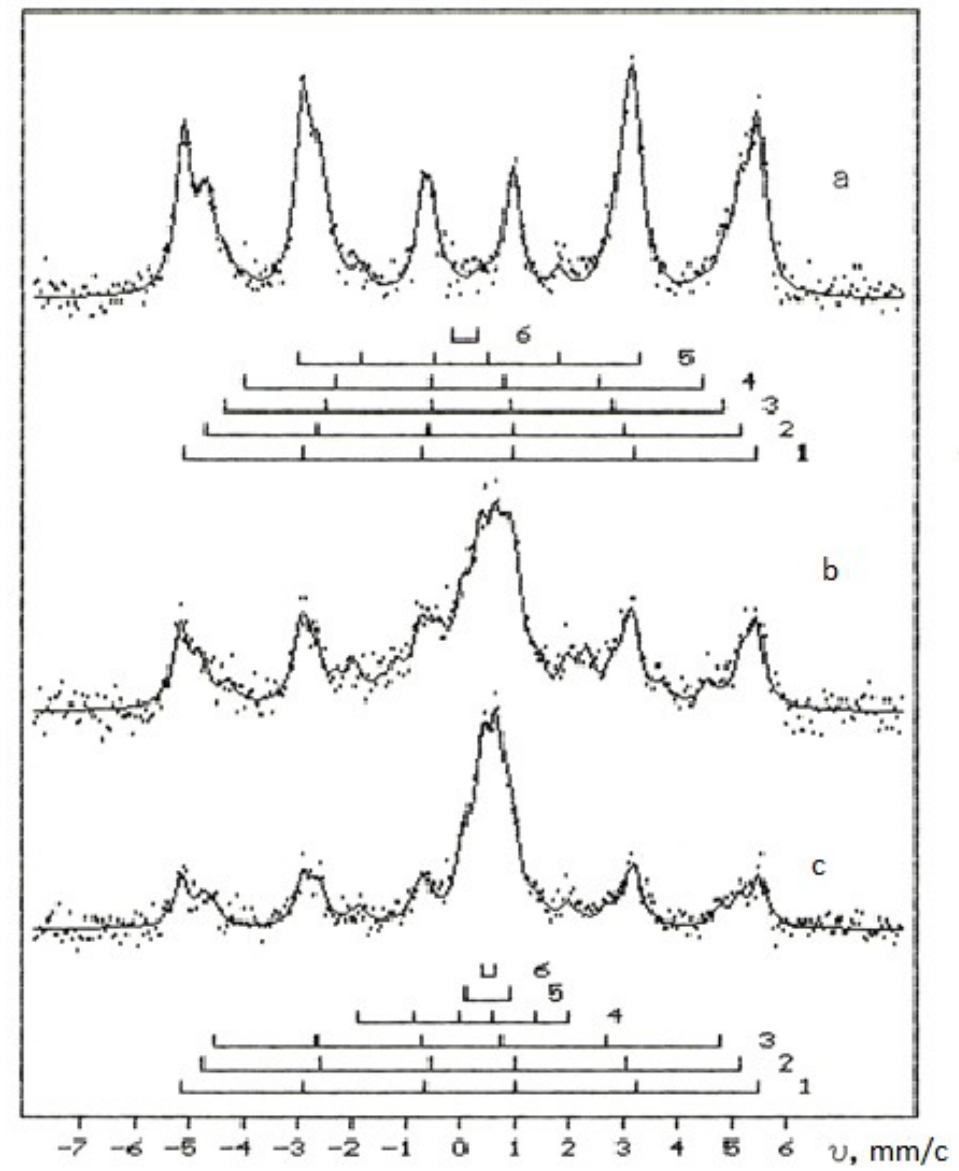

Fig. 1: NGR-Spectra of Cast Iron in the Initial State (a) and After Irradiation

$\left[\mathrm{N}^{+}\right.$ions at $\mathrm{j}=5 \mu \mathrm{A} / \mathrm{cm}^{2}$ and $\mathrm{D}=(2$ and 5$) \times 10^{17}$ ions $/ \mathrm{cm}^{2}(\mathrm{~b}, \mathrm{c})$. a): 1), 2), 3), 4) - ferrite; 5) - cementite $\left.\theta-\mathrm{Fe}_{3} \mathrm{C} ; 6\right)$ - residual austenite and microfine carbides Fe-C-Si; (b, c): 1), 2), 3) - ferrite; 4), 6) - $\varepsilon$-carbonitrides; 5) - microfine carbides Fe-C-Si.] 


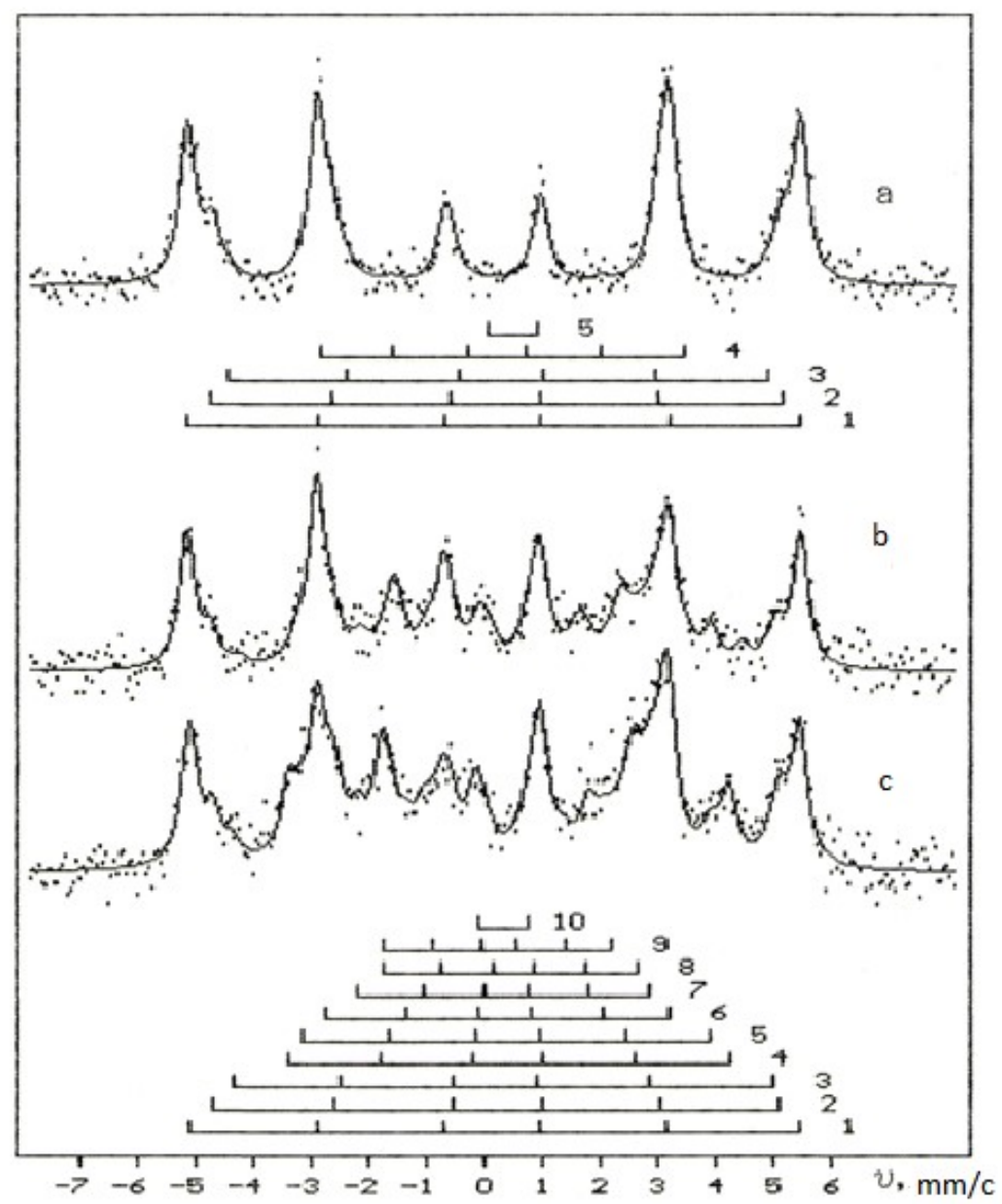

Fig. 2: NGR-Spectra of Cast Iron in the Initial State (a) and After Irradiation $\left[\mathrm{N}^{+}\right.$ions at $\mathrm{j}=5 \mu \mathrm{A} / \mathrm{cm}^{2}$ and $\mathrm{D}=(2$ and 5$) \times 10^{17}$ ions $/ \mathrm{cm}^{2}(\mathrm{~b}, \mathrm{c})$.

(a): 1), 2), 3), 4) - ferrite; 5) - cementite $\left.\theta-\mathrm{Fe}_{3} \mathrm{C} ; 5\right)$ - residual austenite and microfine carbides $\mathrm{Fe}-\mathrm{C}-\mathrm{Si}$; $\left(\right.$ b, c): 1), 2), 3) - ferrite; 4) - $\left.\left.\left.\left.\left.\left.\varepsilon-\mathrm{Fe}_{3} \mathrm{~N} ; 5\right)-\gamma^{\prime}-\mathrm{Fe}_{4} \mathrm{~N} ; 6\right)-\theta-\mathrm{Fe}_{3} \mathrm{C} ; 7\right), 8\right), 9\right), 10\right)-\varepsilon$-carbides and carbonitrides.]

The spectra of the samples irradiated at $\mathrm{j}=5 \mu \mathrm{A} / \mathrm{cm}^{2}$ are distinguished by the presence of an intense paramagnetic component against the background of the initial ferrite structure (Fig. 1 b, c). With an increase in the implantation dose, the fraction of the paramagnetic component in the resulting spectrum increases $\left(\sim 26 \%\right.$ at $\mathrm{D}=2 \cdot 10^{17}$ ion $/ \mathrm{cm}^{2}, 34 \%$ at $\mathrm{D}=5 \cdot 10^{17}$ ion $/ \mathrm{cm}^{2}$ and $42 \%$ at $\mathrm{D}=1 \cdot 10^{18}$ ion $\left./ \mathrm{cm}^{2}\right)$. At an implantation dose of $2 \cdot 10^{17}$ ion $/ \mathrm{cm}^{2}$ in the NGR spectrum, along with the paramagnetic component, additional magnetic components (sextets) characteristic of $\gamma^{\prime}$-nitride and $\varepsilon$-carbonitride $(\sim 5 \%$ and $21 \%$ ). A sextet corresponding to carbonitride is also observed in the spectrum of cast iron at an implantation dose of $5 \cdot 10^{17}$ ion $/ \mathrm{cm}^{2}(\sim 9 \%)$, and at $\mathrm{D}=1 \cdot 10^{18}$ ion $/ \mathrm{cm}^{2}$ the NGR spectrum of the irradiated alloy consists only of the paramagnetic and ferrite components.

The results of mathematical processing show that the paramagnetic component of the considered spectra forms two doublets. The parameters of the first doublet make it possible to attribute it to finely dispersed $\varepsilon$-carbides of the $\mathrm{Fe}$-C-Si type. The second doublet, according to the parameters of the hyperfine structure (HFS), can correspond to paramagnetic nitride (carbonitride) $\varepsilon-\mathrm{Fe}_{2}+\mathrm{x} N$ with $\mathrm{x} \rightarrow 0$. (It is known that at $\mathrm{x} \leq 0.3$, the ferromagnetic $\varepsilon$-phase turns into paramagnetic).

The spectra of the samples irradiated at $\mathrm{j}=50 \mu \mathrm{A} / \mathrm{cm}^{2}$, reveal additional components corresponding to the nitrides $\varepsilon$ $\mathrm{Fe}_{3} \mathrm{~N}$ and $\gamma^{\prime}-\mathrm{Fe}_{4} \mathrm{~N}$ (Fig. 2 b, c). At an irradiation dose of $\mathrm{D}=2 \cdot 10^{17} \mathrm{ion} / \mathrm{cm}^{2}$, the fractions of the sub-spectra of the $\varepsilon^{-}$ phase and $\gamma^{\prime}$-phase in the resulting spectrum are $6 \%$ and $12 \%$, and at an implantation dose of $5 \cdot 10^{17}$ ion $/ \mathrm{cm}^{2}-17 \%$ and $8 \%$, respectively. The mathematical processing of the NGR spectra also indicates the presence of the paramagnetic and magnetic components with the parameters of the HFS distributed over a rather wide range of values. The HFS parameters of these components allow us to bind them with hexagonal $\varepsilon$-carbides and carbonitrides $\varepsilon-\mathrm{Fe}_{2}+\mathrm{x}(\mathrm{N}, \mathrm{C})$. 


\section{Conclusion}

The comparison shows that at an ion current density of $5 \mu \mathrm{A} / \mathrm{cm}^{2}$ in the surface layers of cast iron there is a greater number of new phases than at $\mathrm{j}=50 \mu \mathrm{A} / \mathrm{cm}^{2}$. Moreover, under conditions of lower ion current density, mainly finely dispersed $\varepsilon$-carbides of the $\mathrm{Fe}-\mathrm{C}$-Si type are formed, as well as paramagnetic $\varepsilon$-nitrides (carbonitrides), which are close in composition to $\mathrm{Fe}_{2} \mathrm{~N}$. With an increase by an order of magnitude of the ion current density in the implanted layer, the fraction of $\gamma$-nitrides increases, and $\varepsilon$-carbides turn out to be in the ferromagnetic state. In addition, the composition of $\varepsilon$-nitrides (carbonitrides) formed in this case approaches $\mathrm{Fe}_{3} \mathrm{~N}$, which makes them also ferromagnetic.

These differences can be explained by a change in the dominant processes in the irradiated material. Probably, at an ion current density of $5 \mu \mathrm{A} / \mathrm{cm}^{2}$, radiation-induced segregation and ionic mixing, which determine the dynamics of phase formation, predominate in the surface layers of cast iron. The process of radiation-induced segregation caused by the movement of point radiation defects to sinks leads to the accumulation of nitrogen and silicon atoms at the boundaries of graphite inclusions in cast iron, which increases the likelihood of nucleation of $\varepsilon$-nitrides enriched with nitrogen, as well as finely dispersed $\varepsilon$-carbides of the type Fe-C- Si.

With an increase in the ion current density by an order of magnitude, the processes of recombination of point radiation defects are enhanced, which is due to the effect of interstage, dynamic annealing, and also to the heating of the sample due to an increase in the dissipated power. As a result, the processes of migration of defects to sinks, responsible for radiation-induced segregation and phase formation at graphite boundaries, are suppressed. The process of thermal diffusion becomes dominant, which promotes the unification of finely dispersed $\varepsilon$-carbides, and also leads to a redistribution of nitrogen in the implanted layer and to the formation of phases with a lower content of it $\left(\gamma^{\prime}-\mathrm{Fe}_{4} \mathrm{~N}\right.$ and $\varepsilon$ $\mathrm{Fe}_{2}+\mathrm{x}(\mathrm{N}, \mathrm{C})$ with $\left.\mathrm{x} \approx 1\right)$. From changes in the phase composition of the irradiated layers, one can expect changes in their properties.

\section{Acknowledgments}

The work is performed according to the Russian Government Program of Competitive Growth of Kazan Federal University.

\section{References}

[1] F.F. Komarov Ion implantation in metals. - M.: Metallurgy, 1990. - 216 p.

[2] I.A. Akhiezer, L.N. Davydov Introduction to the theoretical radiation physics of metals and alloys. - Kyiv: Naukova Dumka, 1985. - $141 \mathrm{p}$.

[3] A.V. Bely, Ion beam nitriding of metals, alloys, and ceramic materials. - Minsk: Belarus. Nauka, 2014. - 411 p.

[4] G. Longworth, N. Hartley, Mossbauer Effect Study of Nitrogen-Implanted Iron Foils // Thin Solid Films. - 1978. V.48. - No. 1. - pp. 95-104.

[5] G. Principi, P. Matteazzi, E. Ramous, G. Longworth, Mossbauer Surface Study of Nitrogen-Implanted High Carbon Martensite // J. Mater.Sci. - 1980. - V.15. - pp. 2665-2668.

[6] D. Rauschenbach, K. Hohmuth, Formation of Iron Carbonitride and Iron Carbide Phases During Nitrogen Ion Implantation // Crist.Res. Technol. - 1984. - V.19. - No. 11 - pp. 14255-1431.

[7] V.V. Kirsanov, A.L. Suvorov, Yu.V. Trushin, Processes of radiation defect formation in metals. - M.: Energoatomizdat, 1985 .- 272 p.

[8] E.R. Akst, E.S. Romanov, N.G. Ivoilov, Study of phase formation processes in nitrogen-implanted iron-carbon alloys // Physics, chemistry, and mechanics of surfaces, 1995. - V.11. No. 6, - pp. 770-778.

[9] E.V. Vasilieva, O. Yu. Usanova, B.Sh. El-Bekay, E.V. Lukyanenko, E.R. Akst, The influence of the shape of graphite inclusions on the phase formation processes and properties of cast irons subjected to ion implantation // Metals, 1996. - No. 5. - pp. $128-134$.

[10] E.V. Vasil'eva, O.Yu. Usanova, B.Sh. El'-Bekai, E.V. Luk'yanenko, E.R. Akst, Effect of graphite shape on the formation of phases and properties of irons finally to ion implantation // Russian Metallurgy (Metally), 1996. No. 5. - pp. 107-112.

[11] E.R. Akst, Changes in the phase composition and properties of cast irons upon implantation of nitrogen ions into the surface layers // Socio-economic and technical systems: research, design, optimization. - Nab. Chelny: Publishing House of Scientific Research Institute of K (P) FU, 2015. - V. 1. No. 1 (64). - pp. 13-25.

[12] E.R. Akst, Structural and phase transformations in cast irons when implanted into the surface layers of nitrogen ions // IOP Conference Series: Materials Science and Engineering, 2015. - V.86 (1). - P.012038. 